\title{
Cross-Border Tomato Trade and Susceptibility to HIV Infection: A Case of Ghana-Burkina Faso Tomato Traders: A Qualitative Study
}

\section{Koxwell Kaba Tiire ${ }^{1}$, Alexander Suuk Laar², Daniel K. Azongo ${ }^{3}$}

${ }^{1}$ St. Vincent College of Education, P. O. Box 184, Yendi, Ghana

${ }^{2}$ C/O PATH-Ghana, PMB CT 307, Cantoment, No.74 Osu Badu Street, Airport West, Ghana

${ }^{3}$ Navrongo Health Research Centre, Ghana Health Service, Navrongo, Ghana

\begin{abstract}
One of the core objectives of establishing the West African regional integration body (ECOWAS) is to promote cross-border trade and cooperation among member states. HIV infection has been found to be associated with population mobility, including cross- border trade and labour migration. The objective of this study is to provide evidence based recommendations for government and other stakeholders to respond to and address the HIV/ AIDS epidemic in a multi-disciplinary approach. Qualitative method was used to collect data for the study. It involved 2 Focus Group discussions, 15 in-depth interviews with women tomato sorters and 3 Key Informant interviews with tomatoes market Queens. A purposeful sampling method was used to select eligible participants. The data were analyzed using a thematic framework approach. The women admitted that poverty, household's food insecurity and household assets were the main motivational factors for them engaging in the cross border tomato trade. This study has highlighted the risk of HIV susceptibility among cross border tomato traders in rural Ghana. Improving the knowledge and livelihood opportunities of women and young girls engaged in the cross border tomato trade, calls for a comprehensive community- based educational campaigns targeted at mobile women engaged in the cross border trade in the study area.
\end{abstract}

Corresponding author: Alexander Suuk Laar, C/O PATH-Ghana, PMB CT 307, Cantoment, No.74 Osu Badu Street, Airport West, Ghana, Tel No: +233-201270134,E-mail: laar.alex.suuk@gmail.com

Received: January 14, 2020, Accepted: January 22, 2020, Published: January 25, 2020

Keywords: Cross-Border, Tomato Trade, HIV Infection, Case, Ghana-Burkina, Faso Tomato Traders

\section{Introduction}

Agriculture is the backbone of food security and livelihood for millions of rural households including men and women. People whose agricultural livelihoods are secure are able to produce sufficient food to meet their household food requirement and other important social and economic needs. When households are faced with food insecurity and limited income opportunities, they are compelled to undertake several risky activities in or- der to be employed and earn income to be able to provide for their households. This is particularly the case for women and girls from rural areas in less developed countries. This difficult situation, among others factors put women and girls at higher risk of HIV infection as they are forced to migrate from their households in search for waged labour to earn money to complement the household income. Because of women limited access to, and control over resources and assets in the 
Citation: Kaba Tiire K, et al.(2019) Cross-Border Tomato Trade and Susceptibility to HIV Infection: A Case of GhanaBurkina Faso Tomato Traders: A Qualitative Study. Journal of Infectious Diseases \& Case Reports. SRC/JIDSCR/101. DOI: doi.org/10.47363/JIDSCR/2020(1)101

household, women and girls are also more susceptible to HIV infection. This is particularly common in rural areas where socio-cultural practices of property grabbing after the death of a woman's husband and lack of knowledge on HIV are high [1-3].

HIV infection has been found to be associated with population mobility, including cross- border trade and labour migration. The movement of people from areas of high prevalence to areas of low prevalence may result in levelling effects in the distribution of HIV infection. Several factors have been reported to account for the association between mobility and susceptibility to HIV infection including casual and multiple concurrent partnerships, increasing sexual risk behaviours, reduced access to health services and means of prevention such as condoms [4-6].

One of the core objectives of establishing the West African regional integration body (ECOWAS) is to promote cross-border trade and cooperation among member states. Therefore, over the last few years, ECOWAS has encouraged and strengthened the development of crossborder cooperation by encouraging free movements of people and goods within member's states Based on the ECOWAS agreements, Ghana and Burkina Faso has developed and maintained bilateral cooperation allowing the free movements of their citizens. This phenomenon has resulted in the increased influx of temporary migrants engaged in various forms of economic and social activities in both countries. One of such economic activity that is increasingly gaining prominence is the buying and selling of tomatoes. Statistics from the Customs, Excise and Preventive Service of Ghana at the Paga/Ghana-Burkina Faso boarder post indicate that during the 2008 to 2009 tomatoes farming season, Ghana imported about 6,562.43 metric tons of tomatoes from Burkina Faso [9]. This constitutes over 60 per cent of the total amount of tomatoes transported from Northern Ghana to the consuming markets in Southern Ghana [7-9].

In the late 1990s and early 2000, the tomato Market Queens who use to buy tomatoes from farmers in Navrongo now organize the labour needed to sort and load the tomatoes from Burkina Faso which are then transported to the major urban centre in southern Ghana, such as Accra and Kumasi, where they are distributed to retailers, who sell them to the consumers. One important marketing challenge faced by farmers in the region is the competition from OuagadougouBurkina Faso tomato producers. Farmers complained that Market Queens prefer the Ouagadougou tomatoes to the tomatoes from the study region. This situation therefore made majority of Young men and women to abandon farming in Navrongo and join the market queens to Burkina Faso as tomato sorters.

For the past, research in the tomato industry in Ghana has focused on the challenges with tomatoes production; marketing and distribution of the commodity However, the association between food security, mobility of rural women and susceptibility to HIV infection are less researched. It is against this background that this study was undertaken to fill this critical evidence gap to assess rural women participation in cross border tomato trade between Ghana and Burkina Faso and susceptibility to HIV infection $[8,10]$.

\section{Methods \\ Study Settings}

The study area is Navro-pungu, consisting of several rural communities in the Kassena-Nankana District of Upper East Region. Navro-pungu has been chosen because most of the women constitute a greater number of mobile people who cross the border as tomatoes sorters [11]. Ghana as a country is located in West Africa with a total population of about 24 million people. The country borders Burkina Faso to the north, Togo to the east, Cote d'Ivoire (Ivory Coast) to the west and the Gulf of Guinea to the south. Ghana has ten regions of which Upper East, Upper West and Northern Region forms Northern Ghana, originally comprised the former Northern Territories during the British colonial rule. These three regions by economic indicators are the poorest in Ghana and are comparable in terms of poverty level to some of the poorest countries in the West Africa, notably Burkina Faso and Mali, Senegal and Ivory Coast. The Upper East region also has nine administrative districts with the regional capital at Bolgatanga. The current study was conducted in the Kassena-Nankana District. Figures 1 \& 2 depict Maps of Ghana and Kassena-Nankana District. 
Citation: Kaba Tiire K, et al.(2019) Cross-Border Tomato Trade and Susceptibility to HIV Infection: A Case of GhanaBurkina Faso Tomato Traders: A Qualitative Study. Journal of Infectious Diseases \& Case Reports. SRC/JIDSCR/101. DOI: doi.org/10.47363/JIDSCR/2020(1)101

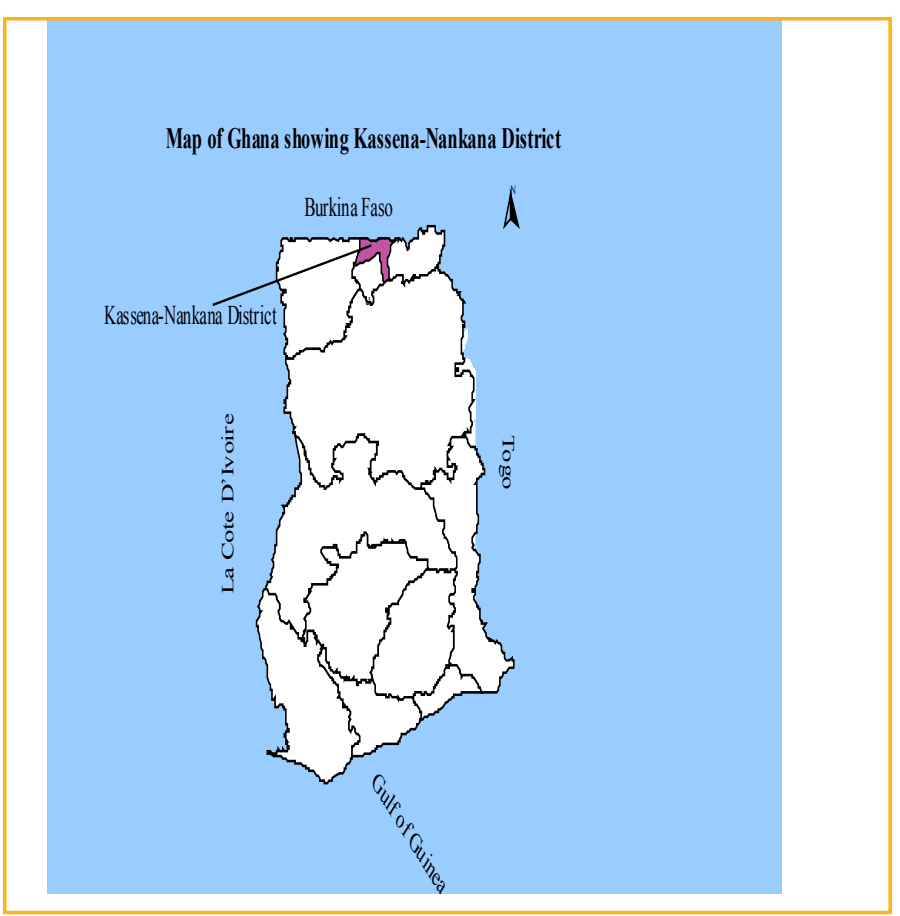

Figure 1: Map of Ghana showing KND.

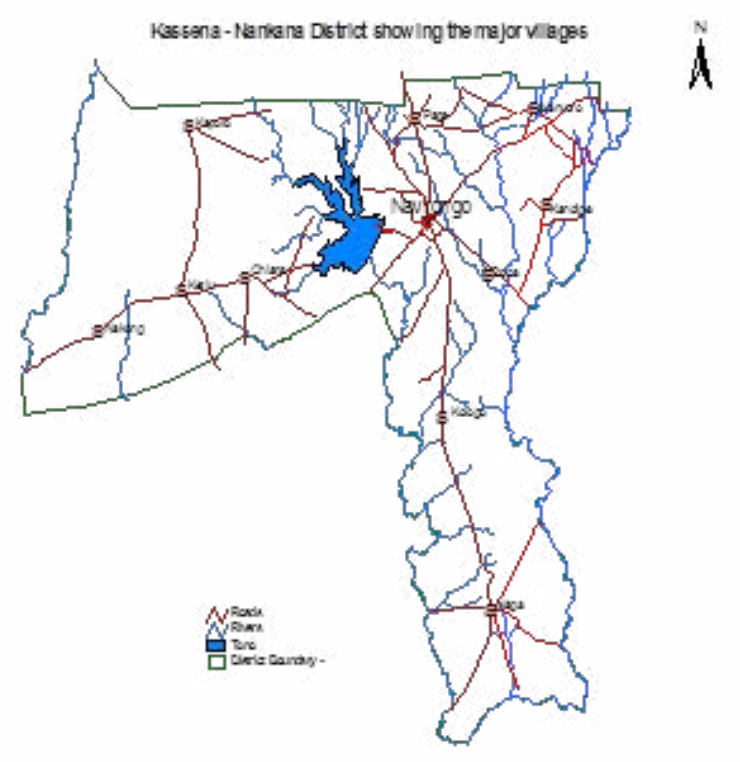

Figure 2: Map of KND showing the major villages.

\section{Study Design}

In order to answer the research questions of this research, primary data was collected from the field. A qualitative method was used to collect the data. It made use of Focus Group Discussions (FGDs), indepth interviews (IDIs) and Key Informant Interviews
(KIIs). A purposeful sampling method was used to select eligible participants. A qualitative method was chosen to help explore deep into the research questions and the phenomenon under investigation [12].

\section{Data Collection}

In all, 15 IDIs (women tomatoes sorters), 2 FGDs (13 women tomatoes sorters) and 3 KIIs with tomatoes market Queens were interviewed for this study.

\section{Inclusion Criteria}

1. Rural women and young girls of the ages of 18 years and above.

2. Rural women and girls selected to sort tomatoes by the tomato market Queens.

3. Women tomatoes sorters and tomatoes market Queens who have consented and were willing to participate in the study.

To elicit more useful or detailed information from a participant during the data collection, the researcher probed the participants by encouraging them to explain their reasons for engaging in cross border tomato trade, Knowledge on risk factors for HIV infection, perception of HIV susceptibility and social activities they engage in at the field. The questions were directed at exploring their reasons, and follow-up questions were asked for clarity of any ambiguity.

\section{Data Analysis}

The audio recordings were transcribed verbatim from the local languages by an expert. Following transcriptions, content analysis was used to review and code the transcripts. The coded transcripts and field notes were read, noting important issues emanating from the data and classifying them into themes in table forms. Emerging themes were identified and analyzed using thematic framework approach [13].

\section{Results}

\section{Reasons for Rural Women Engaging in Cross Border} Tomato Trade.

The women admitted that poverty and household's food insecurity, household assets and child education as the reasons as the main motivational factors for engaging in cross border tomato trade. 
Citation: Kaba Tiire K, et al.(2019) Cross-Border Tomato Trade and Susceptibility to HIV Infection: A Case of GhanaBurkina Faso Tomato Traders: A Qualitative Study. Journal of Infectious Diseases \& Case Reports. SRC/JIDSCR/101. DOI: doi.org/10.47363/JIDSCR/2020(1)101

In the discussion it was reported that women spend several days engaging in the cross border tomato trade to earn some income to supplement the needs of the family. They indicated that they spend an average of three and four days outside the home when they travel. This is supported in the following quote.

Truly, I am engaged in this business because we don't have enough food to eat, we are living in abject poverty this is because my parents cannot do any work again, they are weak and these time the harvest are not good enough and we always have food shortage every year. During this period I spend several days outside my family."(Tomato Sorter) Most of the participants, said their husbands should be the sole provider's of food to feed the households. However, they also admitted that it is also their responsibility to support their husbands to provide for the household needs.

"It is the duty of the children's father to provide food but nowadays if you look up to only your husband to provide for you and your children you will suffer, so both of you must go out and earn something to keep the household alive" (Married Tomato trader).

"It is my father and mother duty to provide food for the whole family but they are old and weak and cannot work again, times are also hard and we the children also have to work to support the family and ourselves" (Unmarried Tomato Sorter).

Some women also said that it is hard to have enough food in the household to eat when they don't have any paid work doing in addition to the farming. So many of them have to engage in this trade to earned money to support their husbands and their own needs.

"It is the duty of the children's father to provide food but nowadays if you look up to only your husband to provide for you and your children you will suffer, so both of you must go out and earn something to keep the household alive" (Married Tomato trader).

"It is my father and mother duty to provide food for the whole family but they are old and weak and cannot work again, times are also hard and we the children also have to work to support the family and ourselves" (Unmarried Tomato Sorter).

Some women also said that it is hard to have enough food in the household to eat when they don't have any paid work doing in addition to the farming. So many of them have to engage in this trade to earned money to support their husbands and their own needs.

\section{Knowledge on Risk Factors for HIV Infection}

The study revealed that all the participants were aware of the signs and symptoms of HIV/AIDS and the mode of HIV transmission.

"Apart from sex, I think it also depends on your living style that will make you get this illness. At times it depends on your mode of dressing which makes you attracted to men. If you can't discipline yourself and going round looking for money from men, they will also want to sleep with you before they give food or the money" (Tomato Sorter)

For the question which assessed the knowledge of the participants on HIV and the risk of infection, about 80 percent of them said poverty made them to travel and get involve in risky sexual behaviour that makes them susceptible to HIV infection.

"What you said is true because I know some women do engage in sex for money which is prostitution and a source of income for them, they don't do it for people to see, amongst us I know women who sleep with men for money or for them to buy them mobile phones. All these things can make them get HIV if they don't protect themselves well" (Tomato Sorter).

\section{Perception of HIV susceptibility}

For the question on the perceived susceptibility to HIV infection, the participants perceived the young girls and the unmarried women as been susceptible to HIV infection than the aged and the married women.

"It is the unmarried young girls who the men admire most because they look more appealing and also not engaged. Any man can approach them since they are not attached to any permanent man". "The married women and the women who are nearing or have reached their menopause are not attracted to men as compared to the young and the unmarried women because they are attached or have started developing wrinkles on their faces"

One of the objectives of this study was to find out whether men (loading boys) have influence in determining who is selected for the trip. In response to the question on the role and influence of the men in the selection process was given in the following quote: 
Citation: Kaba Tiire K, et al.(2019) Cross-Border Tomato Trade and Susceptibility to HIV Infection: A Case of GhanaBurkina Faso Tomato Traders: A Qualitative Study. Journal of Infectious Diseases \& Case Reports. SRC/JIDSCR/101. DOI: doi.org/10.47363/JIDSCR/2020(1)101

"The women and the men always meet at the border here in Paga to look for a truck to join. So when these Market women come, they select the strong men because the nature of the work requires people who are strong enough to load the heavy boxes of tomatoes onto the truck" (Tomato Sorter).

On the other hand, some were of the view that it was the market women who do the selection and are always looking for hardworking and experienced women. One of the women has this to say on the selection process.

For the women, they select the hard working ones. In some instance, where they have no idea as who is hard working and who is not, they allow a woman whom they have worked with before to select her colleagues who are also hard working like her. That is how they do the selection. I can say that the men alone don't always do the selection" ((Tomato Sorter).).

That in instances when they have no idea as to who is hard working and who is not. They allow their loading boys or driver's to select women for the trip.

"The number of women who always want to go there are many and the cars are few and they can't also take everyone. So sometimes, the market women ask the loading boys to select the hard working ones and you know men, they take opportunity to include their girlfriends and leave those of us they considered as old or women with children (Tomato Sorter).

We hear that at times some of the women especially those that want to always be selected do give themselves to the boys. And at times too they select their sister's and friend's not only their girlfriend's" (Tomato trader). "Yes, the loading boys always want to have sex with the young girls before they will select you and when you refuse they will remove you from the truck and say it is full when it is not, they want to pick those girls that will sleep with them over there" (Tomato Sorter). These findings were confirmed in the FGDs and the key informant interview with the tomato market queen.

"I know that those women especially the young girls and the unmarried women who after a good number of times have not been selected and still want to go at all cost in order to earn some money are likely to give themselves to the men who do the selection in order to win their favour." (Tomato market Queen).

\section{Social Activities among tomato sorters}

Among the many issues explored in this study, one of them investigated tomato trader's social activities when they travel to Quahigouya to buy the tomatoes. It was found that in most situations the traders spend about three to four days in Quahigouya looking for tomatoes to buy. That sometimes they do socialize by entertaining themselves in drinking bars. Some did indicate that this normally results in having multiple sexual partners.

"Yes there are times a woman can have more than one sexual partner because at times you can have many problems to solve with money and one man cannot help you solve all your problems. I know of some women here who have been changing men any time we travel. Some of them also friend the tomato farmers in order to get some tomatoes to sell back home. I have never been with more than one partner in my life before and I will not do that because of money" (Tomato Sorter).

When the women were asked whether out of surprise they have been involved in acts which predispose them to HIV susceptibility, they all gave negative responses. One young trader has this to say.

Yes' I am not married and why won't they try me? They have been trying me since I started going there but I will never give in. I prefer not to be selected than to give myself out to men some of whom are not even economically better than me" (Tomato Sorter).

\section{Discussion}

The results from the study show that rural women engaged in the cross border tomato trade are susceptible to the HIV infection. This is because most of them involved themselves in risky sexual behaviours with the men they interacted with for monetary favors. There are extensive and well documented literatures on the relationship between poverty and HIV/AIDS. In the context of HIV, poverty increases ones susceptibility to HIV in several ways as gathered by this research and other studies. This study revealed that poverty and food insecurity were the main reasons that cause rural women and young girls to engage in the cross border tomato trade. A report published in Ghana shows that over 1.2 million Ghanaians, representing five percent of the population, are faced with food insecurity and about 34 percent of this population can be found in the Upper West and 15 percent in the Upper East region of Ghana, the region of this study [14-17]. 
Citation: Kaba Tiire K, et al.(2019) Cross-Border Tomato Trade and Susceptibility to HIV Infection: A Case of GhanaBurkina Faso Tomato Traders: A Qualitative Study. Journal of Infectious Diseases \& Case Reports. SRC/JIDSCR/101. DOI: doi.org/10.47363/JIDSCR/2020(1)101

It was found that in some instances women were selected for the trip based on sexual favors. Poverty has been one of the driving factors responsible for the perpetuation of the high levels of mobility and susceptibility to HIV infection among women who engaged in itinerary trade in Ghana [16]. The high level of seasonal unemployment in rural Ghana couple with competition for jobs could force many women to engage in transactional sex out of necessity as observed elsewhere. Evidence has shown that many poor rural households in the study area are characterized by weak financial resources, low levels of education and few employable skills [1]. Therefore, under these challenging circumstances, the women often adopt different coping mechanisms which inadvertently make them susceptible to HIV [14]. The practices of taking men as partners for financial reasons and jobs opportunities have been reported in Ghana by Ankomah. Ankomah argues that sexual exchange is a recent phenomenon that represents an economic survival strategy for most poor and unsecured women [18-19].

The study also examines the relationship between marital status and susceptibility to HIV. The findings showed that unmarried women perceived themselves to be more susceptible to HIV infection compared to their married and divorced/separated. It is found that marital disruption through separation, divorce and widowhood results in more single, female-headed households who have to struggle in order to provide for their households. In the traditional Ghanaian setting, married women are expected to remain faithful to their partners all the time. Men are also not expected to intentionally pursue someone's wife. These findings were confirmed in a study investigating the relationship between marital status and HIV infection [19-21].

It was found that social centres like the drinking bars and night clubs were attractive for risk sex behaviours. These social places have been observed in a previous study in sub-Saharan Africa as attractive centres for mobile populations and therefore, promoting all sort of risk sexual behaviours [22-23].

This study had several limitations. First, twenty eight women were interviewed instead of the initial 30 women due to women unwillingness to participate in HIV related issues for fear of being stigmatized. Future studies should include an extended research component to obtain further information on HIV susceptibilities confronting all key players in the cross border tomato trade between Ghana and Burkina Faso to increase our understanding on the susceptibility to HIV infection associated with cross border tomato trade. This is crucial in guiding governments, stakeholders and other development partners to initiate programs that will reduce HIV infection among them.

\section{Conclusion}

There is no doubt that this study has contributed to support the position that mobile populations and women migrants in particular are at greatest risk of being susceptible to HIV. It is also expected that, the findings of this study would serve as a policy guide for health interventions to address socio-economic and behavioural factors for HIV susceptibility among rural women and young girls who are forced by economic circumstances to engage in cross border tomato trade.

\section{Conflict of Interest: None declared.}

\section{Acknowledgements}

The study has been possible with contributions from diverse sources. My profound gratitude goes to Madam Koos Kingma who served a dual purpose as a course specialization coordinator and thesis supervisor. I wish to express my sincere gratitude to the Netherlands Fellowship Program for the scholarship to pursue the masters' program. Finally, I would like to thank the participants for taking part in this study to share their views, experiences and perspectives. This study would not have been possible without their contribution.

\section{References}

1. Sewnet Y (2015) Causes and coping mechanisms of food insecurity in rural Ethiopia, Agric Biol JN Am 6: 123-133.

2. Inter-Agency Task Force on Rural Women, which is led by FAO, IFAD and WFP, and is composed of the following members: ITC-ILO, SPFII, UNCTAD, UNDP, UNEP, UNESCO, UNFPA, UNIDO, UN Women and WHO. In addition, a substantial contribution was made by UNAIDS to the section on MDG 6 .

3. Dworkin SL, Grabe S, Lu T (2013) Property Rights Violations as a Structural Driver of Women's HIV Risks: A Qualitative Study in Nyanza and Western Provinces, Kenya.Arch Sex Behav 42: 703-713. 
Citation: Kaba Tiire K, et al.(2019) Cross-Border Tomato Trade and Susceptibility to HIV Infection: A Case of GhanaBurkina Faso Tomato Traders: A Qualitative Study. Journal of Infectious Diseases \& Case Reports. SRC/JIDSCR/101. DOI: doi.org/10.47363/JIDSCR/2020(1)101

4. White RG (2003) Commentary: What can we make of an association between human immunodeficiency virus prevalence and population mobility? International Journal of Epidemiology 32: 753-754.

5. Lydie N, Robinson NJ, Ferry B, Akam E, De Loenzien $M$, et al (2004) sexual behaviour, and HIV infection in an urban population in Cameroon, Journal of Acquired Immune Deficiency Syndromes 35: 67-74.

6. White RG (2003) what can we make of an association between human immunodeficiency virus prevalence and population mobility? International Journal of Epidemiology 32: 753-754.

7. ECOWAS 1999: ECOWAS Treaty (www.ecowas.int). 8. Awo MA (2010) Marketing and market queens: a case of tomato farmers in the Upper East Region of Ghana. 9. Ministry of Food and Agriculture, Republic of Ghana, Ghana and Burkina Faso to enter into tomato joint venture, Thursday, June 23rd, $2011 \mathrm{http} / / / \mathrm{mofa}$.gov.gh/ site/?p=2449\#.

10. Amikuzuno J (2009) The Integration of Tomato Markets in Ghana with and without Direct Trade Flows Contributed Paper prepared for presentation at the International Association of Agricultural Economists Conference, Beijing, China.

11. Marketing and market queens: a case of tomato farmers in the Upper East Region of Ghana. Bonn 2010 http://hss.ulb.uni-bonn.de/2010/2335/2335.pdf.

12. KohlbacheR F (2005) The Use of Qualitative Content Analysis in Case Study Research [89 paragraphs] Forum Qualitative Sozialforschung / Forum: Qualitative Social Research 7: 21 http://nbn-resolving.de/ urn:nbn:de:0114-fqs0601211.

13. Vaismoradi M, Turunen H, Bondas T (2013) Content analysis and thematic analysis: implications for conducting a qualitative descriptive study, Nurs Health Sci 15: 398-405.

14. Drimie S (2002) The Impact of HIV/AIDS on Rural Households and Land Issues in Southern and Eastern Africa, A Background Paper prepared for the Food and Agricultural Organization, Sub-Regional Office for Southern and Eastern Africa, August.

15. Parker DC, Jacobsen KH, Komwa MK (2009) A Qualitative Study of the Impact of HIV/AIDS on Agricultural Households in Southeastern Uganda, Int J Environ Res Public Health 6: 2113-2138.

16. Ghana Poverty Reduction Strategy 2003-2005. An agenda for growth and prosperity, Vol 1: Analysis and Policy Statement, February 19, 2003.

17. World Food Program, Republic of Ghana, and Ghana Statistical Service. Comprehensive Food Security \& Vulnerability Analysis (CFSVA) Ghana. April, 2009 http://documents.wfp.org/stellent/groups/ public/documents/ena/wfp201820.pdf.

18. Ankomah A (1999) Sex, Love, Money and AIDS: The Dynamics of Premarital Sexual Relationships in Ghana. Sexualities 2: 291-309.

19. Nabila JS, Fayorsey C (1996) Adolescent fertility and reproductive health behavior in Ghana: A case study of Accra and Kumasi. FADEP Technical Series No: 7, Legon: University of Ghana.

20. Osafo J, Asampong E, Langmagne S, Ahiedeke C (2014) Perceptions of Parents on How Religion Influences Adolescents' Sexual Behaviors in Two Ghanaian Communities: Implications for HIV and AIDS Prevention, J Relig Health 53: 959-971.

21. Ramjee G, Daniels B (2013) Women and HIV in SubSaharan Africa. AIDS Res Ther 10: 30 10.1186/17426405-10-30.

22. Chapman R, White RG, Shafer LA (2010) Do behavioural differences help to explain variations in HIV prevalence in adolescents in sub-Saharan Africa? Trop Med Int Health 15: 554-566.

23. Khan MR, Patnaik P, Brown L, Nagot N, Salouka S, et al (2008) Mobility and HIV-Related Sexual Behavior in Burkina Faso. AIDS Behav 12: 202-212.

Copyright: @2020. Koxwell Kaba Tiire. This is an open-access article distributed under the terms of the Creative Commons Attribution License, which permits unrestricted use, distribution, and reproduction in any medium, provided the original author and source are credited. 